\title{
LA MEDICINA MENTAL EN LA NOVELA CORTA HISPANA: EL CASO DE AMADO NERVO
}

\author{
Christian Sperling \\ Universidad Autónoma Metropolitana, México D.F.
}

\section{RESUMEN}

La evolución de la novela corta de Amado Nervo muestra una comunicación constante con las transformaciones paradigmáticas en el campo de la psicopatología. Las construcciones metaficcionales hacen patente un tratamiento lúdico de algunas ideas clave de la disciplina médica. En algunos casos se superan los estrechos límites de la psicopatología positivista para anticipar planteamientos que adquieren estatuto científico con la psicología moderna.

PALABRAS CLAVE: Amado Nervo. Literatura y ciencia. Psicopatología. Psicología. Novela corta. Positivismo.

THE DISCOURSE ON MENTAL DISORDERS IN THE HISPANIC SHORT NOVEL: AMADO NERVO'S CASE

\begin{abstract}
The evolution of Amado Nervo's novellas shows a constant communication with the paradigmatic shifts in the field of psychopathology. His metafictional constructs foreground a playful treatment of some of medicine's key ideas. In some cases, the narrow limits of positivistic psychopathology are overcome in order to anticipate notions that obtain scientific status with modern psychology.
\end{abstract}

KEY WORDS: Amado Nervo. Literature and science. Psychopathology. Psychology. Novella. Positivism.

\section{CONTEXTOS}

A finales del siglo XIX, el desarrollo de la novela corta y las transformaciones en el campo de la medicina mental se vuelven historias paralelas. Sigmund Freud, por ejemplo, concede que sus estudios de casos se lean como 
novelas cortas ${ }^{1}$. Debido a este carácter literario, el vienés obtiene la reprobación de sus colegas y modifica su escritura para alcanzar mayor cientificidad. La construcción de los fenómenos patológicos por medio de recursos literarios no es exclusiva de la obra freudiana. Durante todo el siglo XIX, muchos de los exploradores de los sueños y del inconsciente emplean metáforas y modelos tomados de la literatura. Al mismo tiempo, el discurso científico permite esbozar una perspectiva epistemológica sobre la poética del fin de siècle para analizar la configuración textual: la trama, los personajes, los motivos, los símbolos, las técnicas narrativas, los posicionamientos ideológicos. La narrativa incorpora elementos científicos y los resignifica. Esta resignificación remite a los límites del potencial heurístico de la ciencia e igualmente prefigura teorías que posteriormente adquieren cientificidad. Por otro lado, la literatura proyecta teorías científicas a otros campos semánticos y los readapta de acuerdo con una intención específica. La evolución ideológica de las novelas cortas de Amado Nervo (1870-1919) permite rastrear las transformaciones de la medicina mental a lo largo de cinco lustros, pues el novelista establece un diálogo fructífero con los fundamentos teóricos y los cambios paradigmáticos del campo científico.

Como cualquier otro fenómeno cultural, la ciencia está vinculada con la episteme de un momento histórico y se relaciona de manera intertextual con otros discursos. En el México porfirista, la idea del progreso penetra en todos los discursos. En los textos modernistas, en cambio, se tiende a desarticular la historicidad implícita en las construcciones teóricas positivistas. La taxonomía psiquiátrica acusa una construcción teleológica de la historia. Los médicos buscaban el eslabón perdido en mexicanos indígenas porque eran considerados representantes arcaicos de la humanidad. En el otro lado de la dicotomía civilización-barbarie, se celebraba la llegada de la modernidad con patologías como la histeria y la neurosis en los enfermos de la clase mediaalta capitalina; enfermedades supuestamente causadas por el alto avance de la civilización ${ }^{2}$. Asimismo, se construyen casos como el del asesino serial, el Chalequero - el Jack the Ripper mexicano-, comprobación de la llegada de

1 Mentzos, S. (1971), Einleitung. En Freud, S., Studien über Hysterie, Fráncfort del Meno, Ed. Fischer, pp. 7-20, p. 9.

2 Gorbach, F. (2007), El encuentro de un monstruo y una histérica. Una imagen para México en los finales del siglo XIX, Nuevo Mundo Mundos Nuevos, 7, s. p. Artículo en línea, disponible en http://nuevomundo.revues.org/document3123.html (consultado el 11 de marzo de 2011). 
los tiempos modernos, ya que elevaba la delincuencia a la altura de Londres ${ }^{3}$. La tautología médica del Porfiriato es la siguiente: los fenómenos patológicos debidos a un exceso de civilización están en continuo aumento, ergo se está viviendo en condiciones modernas. La obsesión progresista se vislumbra en la mayoría de las áreas del conocimiento y les otorga un sentido temporal. También los poetas decadentistas definen su modernidad por medio del estigma positivo de la hiperestesia y de la neurosis. Así, la episteme ordena y configura los enunciados en un momento histórico específico y la literatura aparece como plataforma que hace surgir estos (con)textos, a menudo de manera lúdica y controversial ${ }^{4}$.

La misma época supera los estrechos límites heurísticos de la psiquiatría decimonónica, que comparte el materialismo y la obsesión del positivismo por lo empírico. La disciplina psiquiátrica se abre hacia los modelos hermenéuticos a partir de los primeros esbozos teóricos de la psicología moderna. Parte de esta transición se manifiesta en la pérdida de verosimilitud de los modelos somáticos y hereditarios, así como de las categorías deterministas de la psiquiatría positivista. Se concibe un paradigma diferente sobre la base de explicaciones psíquicas y de la biografía del paciente. Sus experiencias traumáticas inconscientes surgen en el sueño o en el delirio, por lo que el tratamiento orgánico pierde vigencia y el «texto» que producen los pacientes adquiere importancia ${ }^{5}$.

Algunos correlatos de los modelos científicos positivistas se encuentran en el naturalismo. Émile Zola descarta, al igual que los psiquiatras positivistas, la posibilidad de introspección y de actividad anímica ${ }^{6}$. A pesar de ello surgen transfiguraciones del deseo carnal en su obra: sobre todo la figura de la bête humaine, determinada por las categorías de Hyppolite Taine: la raza, la clase y el momento. La distancia del naturalismo frente a una psicología introspectiva se manifiesta en el estudio del carácter de los personajes, que se genera en términos de una autopsia, eco del modelo empírico de la medicina experi-

3 Piccato, P. (2001), 'El Chalequero' or the Mexican Jack the Ripper: The Meanings of Sexual Violence in Turn-of-the-Century Mexico City, Hispanic American Historical Review, 81 (3), pp. 623-651, p. 625.

4 Link, J. (1988), Literaturanalyse als Interdiskursanalyse. En FoHrmanN, J. (coord.), Diskurstheorien und Literaturwissenschaft, Fráncfort del Meno, Ed. Suhrkamp, pp. 284-307.

5 Riceur, P. (1978), Freud: una interpretación de la cultura, México, Siglo XIX; BEUCHOT, M. y BlANCO, R. (1990), Hermenéutica, psicoanálisis y literatura, México, UNAM.

6 Zola, É. (1999), Préface de Thérèse Raquin. En ZolA, É., Écrits sur le roman naturaliste, París, Pocket, pp. 55-61. 
mental de Claude Bernard 7 . A finales del siglo, en cambio, la estética novelesca gira hacia la introspección con el naturalismo espiritual de Joris-Karl Huysmans y con la poética simbolista que reduce el enfoque narrativo a un solo protagonista, cuya percepción distorsiona la representación del mundo diegético ${ }^{8}$. Con ello, se pone en tela de juicio la vigencia de la autopsia como núcleo del modelo analítico, se refina el método introspectivo con técnicas parecidas al stream of consciousness o a la écriture automatique y se rehabilita cierta concepción del inconsciente romántico despojándola de sus connotaciones metafísicas.

\section{REFLEXIONES DEL CRONISTA EN TORNO A LA MEDICINA}

Los modernistas mexicanos reflejan críticamente los patrones de la narrativa naturalista. Nervo contrasta la labor del cirujano con la creación poética en la crónica «Un ideal» (1896) donde se opone la «verosimilitud» de la autopsia y la búsqueda del tópico de la bella muerta, que figura como contrapunto idealista del realismo crudo, simbolizado en la obducción. El anhelado encuentro con ese motivo decadentista es frustrado por los hechos reales: «El 'lindo' cadáver, tuve que confesarlo, era bien feo» ${ }^{9}$. En una columna del periódico La Semana, Nervo es más irónico al comentar que fue Antenor Lescano quien lo llevó a presenciar la autopsia: «Mi amigo tiene una dualidad macabra: doctor y poeta decadente. ¿Se compadecerán ambas cosas? Juzgo que sí. Anatomizar un cadáver y vertebrar una estrofa, ¿quién acertará a hallar oposición en esto?» ${ }^{10}$. La detallada descripción de la autopsia reconstruye la mirada del anatomista y su empeño en la «documentación literaria» ${ }^{11}$ que penetra por debajo de la superficie del cuerpo y recorre la anatomía guiada por el bisturí. El texto muestra cierto desencanto acerca del potencial revelador de la autopsia, ya que el método sólo arroja luz sobre el funcionamiento de los órganos, sobre su utilidad y su mecánica. La conclusión irónica, en

7 FöCKING, M. (2002), Pathologia litteralis: Erzählte Wissenschaft und wissenschaftliches Erzählen im französischen 19. Jahrhundert, Tubinga, Gunter Narr, pp. 170-209.

8 Olivares, J. (1984), La novela decadente en Venezuela, Caracas, Gráficas Armitano, pp. 39-42. 690.

9 Nervo, A. (1991), Obras completas, Madrid, Aguilar, vid. Un ideal, Vol. 1, pp. 689-

10 Nervo (1991), vid. Crónicas en La semana, Vol. 1, p. 799.

11 NeRVo (1991), p. 799. 
cambio, remite a los límites de la psicología literaria contemporánea y pone en entredicho la relación entre lo orgánico y lo psíquico:

Antenor sonreía: ha visto tantas vísceras, que si éstas revelaran los abismos de la conciencia habría que discernirle, además de los títulos de médico y de poeta, el de psicólogo, que ni los más sonados novelistas han logrado merecer en toda su latitud ya que un Bourget, por ejemplo, no hace otra cosa que poner faldas a su espíritu y presentárnoslo luego con el nombre de una condesa $\mathrm{X}^{12}$.

La crónica alude a la posibilidad de rebasar los límites impuestos por las categorías de la escritura naturalista. Esta reflexión nerviana se rebela en contra del determinismo orgánico del positivismo, que proclama la imposibilidad de la introspección psicológica ${ }^{13}$.

Nervo se distancia de la narrativa naturalista y se inserta en los límites de la construcción psicológica inherentes a los modelos anatómicos. En consecuencia, su narrativa elabora una oposición semántica entre la dicotomía autopsia-imaginación y, análogamente, entre lo orgánico y lo psíquico. En relación con los límites de la psicología positivista, debe mencionarse la rehabilitación del inconsciente en el modernismo. El positivismo, en cambio, se apoya sobre modelos materialistas, por ejemplo la craneología y la metáfora del telégrafo para referirse a la tensión nerviosa. Así, la mente opera sobre la base del epifenomenismo de la conciencia, es decir, se esgrime la idea de que lo interior es un mero reflejo de lo exterior ${ }^{14}$. En «De lo inconsciente en la creación literaria» ( $c a$. 1914), Nervo comenta cómo el inconsciente cobra estatuto científico, aunque sigue siendo una función todavía indeterminada:

La "masa mental" [...] el conjunto de las manifestaciones mentales se compone de dos partes: una que se revela directamente y de pronto a la conciencia, y es la que constituye el dominio de la psicología ordinaria, "oficial", y otra de la que no tenemos sino conciencia indirecta [...] Esta segunda parte, que casi no ha sido estudiada antes de los últimos años [...] se ha dado llamar cerebración inconsciente, subconciencia, subliminal, etcétera ${ }^{15}$.

12 NeRVo (1991), p. 799.

13 En relación con este concepto, debe mencionarse el hibridismo que se desprende de la obra de Paul Bourget donde el modelo anatómico naturalista se combina con la introspección, lo que se expresa en la idea de la «vivisection de un état de âme»; cf. MEYER-MinNEMANN, K. (1979), Der spanischsprachige Roman des Fin de siècle, Tubinga, Niemeyer, p. 59.

14 KLEIN, D.B. (1970), A History of Scientific Psychology: Its Origins and Philosophical Backgrounds, London, Routledge, p. 231.

15 NerVo (1991), vid. De lo inconsciente en la creación literaria, Vol. 2, p. 709. 
Esta perspectiva sobre el punto de vista «oficial» se enriquece mediante el tono irónico con el que Nervo suele comentar los «logros» de la ciencia. Además, presenta una extensa colección de citas filosóficas y literarias sobre el inconsciente para relativizar el descubrimiento.

Finalmente, durante el Porfiriato se construyeron nuevos hospitales para recluir a los pacientes que presentan desviaciones mentales de acuerdo con la psicopatología. El dispositivo psiquiátrico penetra en muchos aspectos de la vida cotidiana ${ }^{16}$. Esta transformación le sugiere a Nervo reflexiones sobre la relatividad de los diagnósticos de la locura en tres textos representativos de 1896, año clave en el que se refuerza marcadamente la presencia del discurso psicopatológico en los periódicos y en la literatura. En «Medidas represivas», relaciona el aumento del número de personas locas con la instauración del manicomio. La deducción nerviana es esta: el nuevo enfoque médico produce automáticamente más casos clínicos ${ }^{17}$. En «iAAcromigalia!!» ridiculiza la noción del progreso y su correlación con las enfermedades, asimismo expone el caso de una enfermedad ficticia que consiste en la involución repentina del ser humano al simio. En el trasfondo discursivo de esta sátira de la ciencia se encuentra el debate contemporáneo sobre la degeneración y el sentido histórico retrógrado que adquiere esta patología. La reflexión da lugar a un juego de palabras en el que la «mono-manía» aparece dentro del cuadro clínico de la involución al simio ${ }^{18}$. Otra crónica titulada «Las monomanías» hiperboliza el diagnóstico de la enfermedad al encontrar en cualquier comportamiento cotidiano un indicio de locura. Una larga enumeración combina ámbitos, personajes y actitudes absolutamente dispares — poniendo en tela de juicio la sola posibilidad de esquematizar los fenómenos de la locura-, y culmina con lo siguiente: «Proporcionaría una jaqueca a mis lectores si les diese la lista completa y acaso, acaso les preocuparía, con lo que se despertaría en su cerebro la monomanía de las monomanías, es decir la creencia de que las tenían todas: forma la más compleja y temible de la locura incipiente» ${ }^{19}$. La sátira revela una clara conciencia de la construcción del fenómeno. El texto alude a las instituciones de San Hipólito, Belem y a los jurados en los tribunales, es decir evoca la infraestructura completa (el manicomio y el marco jurídico) que determina y produce los casos de locura. Consecuentemente, la crónica cierra

16 Foucault, M. (2005), El poder psiquiátrico, México, Fondo de Cultura Económica, p. $110-111$.

17 Nervo (1991), vid. Medidas represivas, Vol. 2, pp. 593-594.

18 Nervo (1991), vid. iAcromigalia!!, Vol. 1, pp. 555.

19 Nervo (1991), vid. Las monomanías, Vol. 1, pp. 643. 
con un comentario sobre la relatividad de la razón en la época contemporánea: «Después de todas estas grandes verdades, sólo se ocurre una pregunta: ¿Cuál es la excepción en asuntos de cerebros: la locura o el juicio? Yo creo que lo segundo» ${ }^{20}$. Estas reflexiones sobre la relatividad de la locura son indicios de una ruptura epistemológica que acontece en la última década del siglo XIX, se impone una nueva racionalidad y se transforma la interpretación de la cultura.

\section{EL REGIONALISMO EN CLAVE PSICOPATOLÓGICA}

La primera novela corta de Nervo muestra el declive de su protagonista a partir de la psicopatología. Pascual Aguilera (1892-1893) trata de un personaje del mismo nombre, presa de sus pulsiones irrefrenables. La concepción de la obra es de cuño naturalista, aunque su hibridismo permite atisbos de la sensibilidad de fin de siglo y traba relaciones intertextuales con la tradición regionalista y costumbrista. Como antecedente importante destaca La navidad en las montañas (1871) ${ }^{21}$, donde Ignacio Manuel Altamirano traza una utopía del progreso e idealiza la convivencia pacífica en una comunidad rural. En esta novela fundacional existen varios elementos que permiten hablar de un ejemplo modélico de una comunidad imaginada, de una metonimia de la nación. Entre esos elementos, destaca la trama amorosa que expresa el anhelo por la reconciliación nacional y simboliza la fundación de un enclavado de la civilización en el monte silvestre. La transformación de la naturaleza salvaje en tierra cultivada debe entenderse en el contexto de la dicotomía civilización-barbarie. También se describe un héroe inicialmente caído, que se regenera por su anhelo de una mujer. Pascual Aguilera entreteje un diálogo con este modelo por medio de la inversión de sus características; así, anuncia la distancia de la literatura patriótica que prevalece en el modernismo maduro. La comunidad rural en la novela corta es una manifestación de lo retrógrado, una oposición al pueblo progresista que describe Altamirano. Cabe resaltar el énfasis en el primitivismo de las costumbres y en el determinismo telúrico que subraya la condición atávica de los habitantes. Este tratamiento deshabilita las estrategias narrativas del regionalismo.

En lo que toca a la medicina, Pascual Aguilera hace patente un punto de ruptura en la tradición novelística mexicana, ya que hasta los años noventa el

20 NeRVO (1991), pp. 643.

21 Altamirano, I.M. (2006), La navidad en las montañas. En Para leer la patria diamantina, Negrín, E. (ed.), México, Fondo de Cultura Económica-UNAM, pp. 121-167. 
personaje del cura tiende a representar el sentido común. Mientras en la novela de Altamirano el sacerdote figura como principal impulsor del progreso de la comunidad rural, en Pascual Aguilera garantiza la pervivencia de la estirpe condenada del protagonista. En los años noventa del siglo XIX, se observa una nueva racionalidad, cuya encarnación es el médico, emblema de la secularización. En la novela corta nerviana este personaje dictamina el caso patológico del protagonista: «El médico llegó sólo para diagnosticar una hemorragia cerebral con inundación ventricular, ocasionada por alguna intensa conmoción fisiológica debida a la histeria mental. Pascualillo, víctima hacía tiempo de un erotismo del cerebro, era idóneo candidato para un fin semejante $»^{22}$. A lo largo de la novela se recurre al lenguaje psicopatológico, expresión de esta nueva racionalidad, que clasifica al protagonista como un caso de degeneración hereditaria dentro de una sola generación. Según la psicopatología de la época, esta retrogradación se genera a causa de una modificación orgánica del sistema nervioso que en la novela se deriva del linaje hereditario, pues el mismo Pascual es hijo ilegítimo de una alcohólica y de un progenitor cuya vida excesiva agotó precozmente su fuerza vital. Nervo se distancia en relatos posteriores de las teorías positivistas y elabora una complejidad psicológica mayor en sus personajes.

El texto se inserta en la dicotomía de progreso y salvajismo construida en el discurso psicopatológico de manera que su protagonista alegorice la ineptitud para el progreso. La construcción del personaje pone énfasis en su falta de adaptación en todos los ámbitos: es asociado con los trogloditas, lleva una sexualidad precoz y tiene una obsesión voyeurista. La caracterización de sus desvaríos eróticos recurre a una amplia gama del léxico psicopatológico y a la animalización; esta última es una constante en el naturalismo para señalar la condición atávica de los personajes. El campo semántico médico debe comprenderse en el sentido de una involución: el retorno de un estado civilizado a lo primitivo. Se hace hincapié en que el protagonista muestra un «histerismo sospechoso» desde su niñez y se menciona la «libidinosidad» del «erotómano» o del «ninfómano», que padece finalmente una «horrible hiperestesia sexual» ${ }^{23}$.

Cabe añadir que esta construcción es abiertamente irónica, pues se trata de un juego narrativo con la ingenua fe positivista (que confiaba en la perfectibilidad del género humano) y con la idea de regeneración de un personaje caído a causa de la mujer anhelada. Antes de que el desvarío erótico de Pascual acabe con su vida, viola a su madrastra y así se perpetúa el degenerado linaje.

22 Nervo (1991), vid. Pascual Aguilera, Vol. 1, pp. 157-185, p. 184.

23 Nervo (1991), p. 160, p. 162, p. 170, p. 189, p. 190. 
El amor no correspondido, que en La navidad en las montañas es ascendente y culmina con la celebración de un noviazgo, forma parte del proceso de deterioro en Pascual Aguilera. La novela de Nervo describe la ruptura con el orden de la civilización por medio de un final cuasi incestuoso. Por ello, el relato rompe con el discurso nacionalista sobre los papeles de género; el narrador concluye que «iLa mujer es más amarga que la muerte! ${ }^{24}$. En el mismo sentido, el relato asimila el discurso de la medicina mental y del determinismo psicopatológico de modo que las estrategias narrativas del regionalismo idealista quedan deshabilitadas.

$\mathrm{Si}$ el lema de las ficciones fundacionales latinoamericanas - las novelas que están en la base de la construcción nacional- es «ahora es tiempo de procrear ${ }^{25}$, Pascual Aguilera puede considerarse como una hipérbole de esta máxima. En la segunda mitad del siglo XIX prevalece una visión biológica y determinista de la sociedad que considera que «la atracción sexual era el principio subyacente de todas las formaciones sociales» ${ }^{26}$. En el Porfiriato, a esta ética biológica se agrega cierto imperativo categórico de la procreación, derivado de la obra de Herbert Spencer. Esto se aprecia en los críticos literarios que reaccionan contra la novela nerviana El bachiller. La novela es complementaria de Pascual Aguilera por su oposición a la sexualidad productiva, pues relata el intento fracasado de sublimar la pulsión sexual, lo que sus críticos sancionarán como un atentado en contra de la «sana» moral.

\section{¿UN ESCANDALO CALCULADO?}

En El bachiller (1895) el protagonista es un joven seminarista cuyo afán de pureza espiritual culmina en una autocastración. En lo que toca a la elaboración psicológica, el texto marca un salto cualitativo hacia técnicas introspectivas. Esta novela corta incursiona en el ámbito de la figuración del deseo, pues se describe una alucinación del protagonista a quien se le aparece una

24 Nervo (1991), p. 173. Esta cita bíblica (Biblia Reina Valera, Eclesiastés 7, 26) es emblema de la misoginia con la cual los modernistas mexicanos se posicionan en contra de los primeros movimientos feministas que surgen a partir de los años ochenta del siglo XIX. Cf. Chaves, J.R. (2005a), La mujer es más amarga que la muerte. En ClARK DE LARA, B. y SPECKMANN Guerra, E. (coord.), La república de las letras: Asomos a la cultura escrita del México decimonónico, Vol. I, México, UNAM, pp. 231-244.

25 Sommer, D. (1993), Ficciones fundacionales, Urbina, J.L. y PÉrez, A. (trad.), Bogotá, Fondo de Cultura Económica, p. 35.

26 SOMMER (1993), p. 49. 
mujer fantasmal en un momento devoto frente al altar. Esta alucinación es reflejo de una escritura que opera más allá de lo expresable según los modelos somáticos del positivismo. Al mismo tiempo, el texto muestra una reapropiación subversiva de la psicopatología a la cual se debe su impacto polémico.

Es sabido que se produjo una amplia popularización de la psicopatología positivista y de sus implicaciones culturales por medio de la obra Entartung (Degeneración) (1892-1893), el best seller del médico húngaro-austriaco Max Nordau, donde declara que la totalidad de los artistas contemporáneos son un caso para el manicomio. En otra obra de divulgación científica, la Psico-fisiología del ingenio y del talento (1898), Nordau describe el proceso perceptivo en términos epifenomenistas: «El sistema nervioso central lleva [...] la tarea general de establecer relaciones entre el 'yo' y el 'no yo', o para emplear mejor una expresión menos filosófica, entre el mundo exterior y el individuo, transformar impresiones en conciencia $\gg{ }^{27}$. Esta explicación del funcionamiento del sistema nervioso y, por extensión, de la conciencia, no permite la interferencia del inconsciente; el ser humano es completamente racional. El bachiller, en cambio, deforma el mundo fenoménico a partir de la pulsión de su protagonista. Por tanto, la obra se acerca a los primeros escritos de Freud, pues vincula la libido, una noción energética, y su impacto inconsciente, lo que el positivismo ortodoxo debería rechazar como un planteamiento metafísico.

La narrativa modernista en general comparte este énfasis con los primeros escritos de Freud, aunque puede descartarse una recepción directa o indirecta de la obra del vienés en el caso de Nervo. No obstante, la cercanía a Freud se debe a la recepción de modelos literarios en el modernismo que fomentan la introspección y la transfiguración de la pulsión en el imaginario individual y el inconsciente de los personajes. Entre los modelos literarios más productivos debe mencionarse la narrativa fantástica francesa, de Gérard de Nerval y de Théophile Gautier ( $c f$. infra), que tiende a configurar un segundo nivel ficcional que describe las alucinaciones de los personajes. A ello se suma el interés en la sexualidad de la literatura finisecular.

Al mismo tiempo, El bachiller tiene las características de un estudio de caso degenerativo. A partir de la obra de Nordau la figura del seminarista, al igual que la del solterón y del místico, se concibe en términos patológicos. $E l$ bachiller se centra en la hipersensibilidad del personaje, quien se esfuerza por suprimir su vitalidad. La trama pormenoriza su empeoramiento físico y men-

27 Nordau, M. (1898), Psico-fisiología del ingenio y del talento, México, Ireneo Paz, pp. $39-40$. 
tal, el personaje padece de reuma y anemia; al mismo tiempo, es atormentado por alucinaciones y angustias. En el claustro se muestran las prácticas de mutilación que culminan en la castración. De este modo, la concepción de $E l$ bachiller es híbrida, ya que por un lado se hace referencia a la etiología que surge en el contexto de la teoría de la degeneración; por el otro lado, se muestra el vínculo entre el deseo y su figuración, que permite traerla a colación con la psicología freudiana temprana.

El texto es emblema del giro en la narrativa mexicana, en la cual la racionalidad médica sustituye a las concepciones tradicionales. Aunque la trama se desarrolla en un medio acuñado por los ritmos de la iglesia católica, el protagonista llega a ser representante de una sensibilidad moderna manifiesta en términos médicos: "La fibra mística, esa fibra latente en todo el organismo moderno, habíase estremecido en el seno del silencio» ${ }^{28}$. Esta metáfora puede entenderse como una alusión al tejido nervioso, supuesto origen de la degeneración. De acuerdo con este esquema orgánico, se caracteriza la condición mental del personaje: «Parecía su organismo fina cuerda tendida en el espacio, que vibra al menor golpe de aire ${ }^{29}$. El organismo enfermo figura como arpa eólica y, en consecuencia, los extremos de la dicotomía cuerpo-espíritu coinciden en la imaginación del protagonista.

En los juicios críticos que reproduce Nervo en la segunda edición de 1896 se hace patente que algunos de los críticos contemporáneos identifican la narración como un estudio de caso. Los críticos mexicanos procuran discutirla en términos científicos, de modo que se ponen en relieve las limitaciones del discurso psicopatológico de la época. Así, se aprecia que El bachiller se inserta en la transición histórica entre distintas concepciones de la enfermedad mental. En su crítica del texto, José Riveras amonesta la brevedad del texto y alude al tratamiento del tema patológico: "Sin duda, esta enfermedad no era otra que una de las muchas manifestaciones de la neurosis; pero en esta época de dudas y de análisis, la neurosis debe quedar ampliamente comprobada ${ }^{30}$. Según la etiología positivista, la neurosis se debe a un exceso de civilización, es la enfermedad moderna por excelencia; sin embargo, el tratamiento de la enfermedad en $\mathrm{El}$ bachiller apunta hacia nociones freudianas, ya que las disfunciones psíquicas del personaje se relacionan con la represión de la sexualidad. En consecuencia, el personaje sufre trastornos mentales y alucinaciones.

28 Nervo (1991), vid. El bachiller, Vol. 1, pp. 185-198, p. 188.

29 Nervo (1991), p. 185.

30 Riveras, J.P. (1896), Carta a Amado Nervo. En Nervo, A., El bachiller, México, Tipografía El Nacional, pp. 24-28, p. 26. 
En el texto firmado por el Portero del Liceo Hidalgo, seudónimo del médico Hilarión Frías y Soto, se reprueba la novela corta: «La persecución del ideal es la enfermedad orgánica y secular de la raza humana, tan vieja como ésta, y no del siglo XIX. Y el ideal que hoy enferma, sobre todo a los pueblos educados en la civilización latina, es el misticismo ${ }^{31}$. Para un positivista la noción de la ciencia sobre la condición mental humana significa exclusivamente fisiología y está vinculada a una teleología progresista. La psicología, en cambio, forma parte de la esfera del idealismo. Frías y Soto niega la existencia del inconsciente: «Este joven escritor estudia en la novela más el fenómeno psicológico que sirve de trama a la obra, que el conflicto fisiológico que determina y precipita la tragedia: yo veo en el protagonista un caso patológico, sin duda, porque no creo en la Psiquis, y esta idealidad sólo me parece el conjunto de las funciones orgánicas del sistema nervioso» ${ }^{32}$. En el mismo sentido, en En Turania, de Ciro B. Ceballos, se considera que la verosimilitud de la novela es poco plausible señalando que el desenlace le parece «ilógico» y «antifisiológico», aunque ve al personaje plenamente determinado por sus «animales circunstancias» causa de «la neuropatía que exaltaba los impulsos de la carne $»^{33}$. De este modo, una categoría estética, la verosimilitud, se deriva de la racionalidad médica y el inconsciente no puede ser objeto para su inscripción en el relato.

La reseña de Ezequiel A. Chávez aborda el conflicto entre la carne y el ideal. Según el psicólogo, la novela corta se centra en «ese conflicto perenne entre el yo absurdo, excesivo, que trata de borrar todo de sí mismo para no dejar más que una idea y el no yo inmenso, fecundo y rico» ${ }^{34}$. Esta tensión entre yo y no yo es, según el psicólogo mexicano, un proceso de despersonalización anhelada por el protagonista que desemboca en el ideal de fundirse con el mundo fenoménico. Chávez describe al protagonista como «alma neurótica [...] bajo el imperio demoníaco de una idea fija» ${ }^{35}$. Como veremos, esta amenaza de un elemento irracional apunta hacia la concepción de la literatura fantástica de la época, pues por medio del deseo se abre otro espacio ficcional, más allá de la configuración realista del texto.

31 FríAs y Soto, H. (1896), Carta a Amado Nervo. En Nervo, A., El bachiller, México, Tipografía El Nacional, pp. 33-44, p. 35.

32 FríAs Y SOTO (1896), p. 34.

33 Ceballos, C.B. (2006), En Turania, México, UNAM, p. 60.

34 Chávez, E.A. (1896), Carta a Amado Nervo. En Nervo, A., El bachiller, México, Tipografía El Nacional, pp. 44-50, p. 46.

35 CHÁvEZ (1896), p. 47. 
En varios juicios críticos se distingue la presencia de la ética biológica de Herbert Spencer, fundamento del darwinismo social en el Porfiriato. Respecto de la castración del bachiller se hace patente una marcada ambigüedad en los críticos. Rafael Ángel de la Peña procura construir un ámbito libre para las artes e intenta salvar la novela corta de la acusación de «inmoralidad». Sin embargo, alude inicialmente a Spencer quien «declara obligación moral el ejercicio de las funciones fisiológicas, sin exceso ni defecto y considera como inmorales las acciones que dificultan y con más razón las que imposibilitan cualquiera de las formas de la existencia ${ }^{36}$. Manuel Larrañaga Portugal condena la novela corta «porque esquiva el cumplimiento del deber de los seres creados $[\ldots]$ he meditado con Spencer: es moral el cumplimiento de las funciones naturales, sin exceso ni defecto en ellas» ${ }^{37}$. Finalmente, un comentario de Luis G. Urbina sobre el desenlace del relato muestra el prestigio del que gozó la ética de Spencer, puesto que el mexicano la describe como perfectamente racional, inclusive en oposición a su idea de la ideología burguesa: «Es inmoral, antihumano y antiartístico. Inmoral — hablo de moral alta, no de la hipócrita que proclaman y no practican los lectores burgueses - porque nadie tiene derecho de variar los cursos de la vida que nos manda amar, multiplicarnos y crecer» ${ }^{38}$.

El planteamiento ideológico en la novela corta se configura por medio de un leve pesimismo decadentista y parte de la represión sexual y sus trazos en el inconsciente. El monólogo final de Felipe, que precede a su castración, no deja lugar a dudas de que arremete contra el imperativo de procreación positivista. El monólogo interior muestra la escisión del protagonista mediante el uso de dos voces interiores. Por ello, El bachiller se posiciona sistemáticamente en contra de la ética spenceriana:

Cuchicheábale una voz allá dentro; ¿por qué desertar de una vida donde tus energías pueden significar mucho bien de tus semejantes? ¿No eres acaso una fuerza encaminada, como todas las creadas, a lograr un fin universal? ¿Por qué intentas, pues, defraudar a la Naturaleza, que aguarda tu grano de arena? ¡Qué vas a hacer en un convento! ¡Qué hallarás ahí!

¡Paz! — respondía mentalmente Felipe.

36 De La Peña, R.A. (1896), Carta a Amado Nervo. En Nervo, A. El bachiller, México, Tipografía El Nacional, pp. 8-21, p. 13.

37 Larrañaga Portugal, M. (1896), Carta a Amado Nervo. En Nervo, A. El bachiller, México, Tipografía El Nacional, pp. 22-24, p. 24.

38 Urbina, L.G. (1896), Carta a Amado Nervo. En Nervo, A. El bachiller, México, Tipografía El Nacional, pp. 29-33, p. 32. 
Y la voz íntima añadía:

- ¡Mentira! ¡No la hallarás! La paz es el premio de la lucha. La paz es la recompensa del deber cumplido y tu deber es permanecer en la liza. Naciste para trabajar y amar. En el universo todo trabaja y ama. Desde la abeja que labra el panal, después de besar la rosa, hasta el planeta que, tendiendo eternamente a acercarse al centro de su sistema, se perfecciona a través de los siglos. La atracción, en el espacio, es el amor de astro a astro, y en la tierra el amor es la atracción necesaria que mantiene unidos los seres. ¡Ay de ti si pretendes escapar a esa ley soberana! ¡Ser el rebelde cuando todo se doblega, el soldado que se aparte de la pelea cuando todos combaten y mueren o triunfan ${ }^{39}$.

En este monólogo interior se nota la intercalación polifónica de los lugares comunes del positivismo. Sin embargo, la ironía del pasaje se aprecia solamente al recurrir a la noción de la evolución de Spencer, la cual comprende un principio universal que abarca desde el sistema solar hasta los seres vivos y la sociedad humana ${ }^{40}$. Desde esta perspectiva, el personaje es un escéptico enfermizo que pone en tela de juicio las bases de la sociedad y los fundamentos ideológicos de la ciencia.

\section{UN MELODRAMA BASADO EN LA ANATOMÍA CEREBRAL}

La oposición entre la racionalidad positivista y la sensibilidad poética es el punto de partida para El donador de almas (1899). Esta novela corta marca una distancia de los modelos naturalistas y de su correlato científico, el positivismo, pues ambos son tratados de modo metaficcional y se señala sus límites heurísticos. Por ejemplo, la descripción del interior del cuarto del personaje protagónico - un médico desencantado - muestra una serie de dicotomías entre medicina y poesía, así como entre lo tangible y lo espiritual:

La tarde caía en medio de ignívoma conflagración de colores, y una nube purpúrea proyectaba su rojo ardiente sobre la alfombra, a través de las vidrieras.

Chispeaban tristemente los instrumentos de cirugía, alineados sobre una gran mesa como los aparatos de un inquisidor. Los libros dormían en sus gavetas de cartón con epitafios de oro. Una mosca ilusa revoloteaba cerca de los vidrios e iba a

39 NeRVO (1991), p. 198.

40 Ruíz, R. y Ayala, F. (1999), El núcleo duro del darwinismo. En Glick, T. (coord.), El darwinismo en España e Iberoamérica, México, UNAM, pp. 300-323, p. 300. 
chocar obstinadamente contra ellos, loca de desesperación ante aquella resistencia e incomprensible diafanidad ${ }^{41}$.

La cita alude al bisturí como instrumento que refleja la realidad, es un elemento metaficcional que pone de relieve el modelo mimético y, sobre todo, sus limitaciones. El reflejo de la luz, descrito de manera ostentosamente lírica, manifiesta únicamente tristeza. Así, el momento de aprehensión de lo real, tal como lo caracteriza el destello en los instrumentos, forma parte del desencanto del protagonista. Desde este punto de partida, se describe un proceso de reflexión íntima por parte del personaje que se genera de modo paralelo a un reencantamiento poético del mundo y a un redescubrimiento de la psicología introspectiva. La trama lleva al protagonista del desencanto a la restitución de la imaginación; del credo de un científico materialista a la apertura del horizonte del conocimiento de un creyente en la vida anímica. De esta forma, el texto deja ver el cambio paradigmático en la ciencia, el cual culmina con la fundación de la psicología moderna.

Las mencionadas oposiciones se elaboran por medio de dos personajes complementarios: el poeta y el científico. Los respectivos campos de conocimiento son polarizados, pues el acto de escritura realizado por el médico lo describe el narrador «como queriendo coger el postrer eslabón a que debe soldarse uno nuevo» ${ }^{42}$. Los razonamientos del personaje dentro de las pautas del sistema positivista tienen la connotación de un autoencadenamiento. Asimismo, los tomos de su biblioteca llevan «epitafios» ${ }^{43}$, lo cual permite una asociación entre la falta de vitalidad de la escritura y la del personaje, superada en el desenlace con una nueva concepción del acto de escritura, que adquiere el sentido de una rehumanización del mundo mediante la poesía. Este punto culminante se genera por medio del alma donada, el elemento que le permite superar su estado abúlico. Este espíritu habita una parte de su cerebro y es el eslabón entre ambos personajes: el poeta y el doctor, el donador y el donado 44 .

41 Nervo, A. (2006), El donador de almas. En Nervo, A., El libro que la vida no me dejó escribir, México, Fondo de Cultura Económica-UNAM-Fundación para las Letras Mexicanas, pp. 244-286, p. 245.

42 NERVO (2006), p. 244.

43 Nervo (2006), p. 245.

44 Adicionalmente, el poeta aparenta ser una invención del médico, como si fuese un desdoblamiento de su personalidad, hecho también inherente al ser nombrado: Esteves, que leído por separado resulta ser «Éste ves». José Ricardo Chaves interpreta a este dúo «como el desdoblamiento de una entidad masculina abstracta, enfrentada a otra femenina, y con la que 
Gracias al alma donada, el médico es capaz de diagnosticar infaliblemente cualquier enfermedad y curar a la mayoría de sus pacientes. Los periódicos informan que se sirve de «agentes hipnóticos» y ejerce temporalmente en la Salpêtrière ${ }^{45}$, lugar al cual Charcot otorgaba notoriedad en aquella época. Asimismo, el único caso que se menciona explícitamente es «un complicado caso de histeria» ${ }^{46}$, las demás enfermedades que trata el protagonista permanecen indefinidas. Al igual que Charcot, el protagonista de la novela adquiere fama porque sabe escenificar las dolencias de sus pacientes: «Cuatro años de triunfo, cuatro años de exhibición, de teatralismo médico - el énfasis y el teatralismo son indispensables en el mundo, aun a los verdaderos sabioshabían hecho en él una celebridad universal» ${ }^{47}$. Durante su carrera profesional, el personaje supera las limitaciones de la disciplina y se dedica a la «filosofía de la medicina ${ }^{48}$. Así, se perfila simbólicamente la profesión del psicólogo moderno.

La dicotomía de lo somático y lo psíquico está presente en el juego irónico de los hemisferios cerebrales del doctor, relacionados con la representación del alma. El juego con el esquema positivista se inicia con un comentario del personaje a su cocinera sobre las predilecciones culinarias de éste: «-No sé por qué odia usted los sesos... - Se me figura que me como el pensamiento de las vacas $\rangle^{49}$. Con la muerte del cuerpo del alma donada y su consecuente desencarnación, comienza un juego entre los hemisferios cerebrales, ya que el alma reencarna en el lado izquierdo. La reiteración de la topología cerebral puede entenderse como una serie de alusiones chuscas sobre el supuesto potencial heurístico de la craneología. Atendamos al siguiente comentario del narrador: «La naturaleza [...] tuvo a bien dotarle de una bien calibrada cavidad craneana, repleta de sesos de calidad» ${ }^{50}$. Adicionalmente, el modelo para el alma donada y su cuerpo es la figura histórica de santa Teresa. A finales de

no hay comunión posible de forma permanente» (cf. CHAVES, J.R. (2002), Mujer y erotismo en la prosa inicial de Amado Nervo. En I Coloquio de Amado Nervo: Una obra en el tiempo, Nayarit, CECAN, pp. 49-60, p. 59). Mientras que el médico simboliza la racionalidad científica, el poeta encarna el imaginario que el fin de siglo concibe dentro de categorías patológicas, afirmación que se evidencia en los calificativos de «hiperestesiado» y «desequilibrado» (NERVO (2006), p. 247, p. 270).

45 NeRVo (2006), p. 254-255.

46 NERVO (2006), p. 256.

47 Nervo (2006), p. 256.

48 NerVo (2006), p. 264.

49 Nervo (2006), p. 249.

50 Nervo (2006), p. 263. 
siglo, los éxtasis de la monja representan la posibilidad de la introspección en la psique. En El donador de almas, es posible la curación a partir de las capacidades visionarias de sor Teresa, de su «sueño hipnótico» ${ }^{51}$ o de su «sueño misterioso que en el convento se llamaba éxtasis» ${ }^{52}$.

La presencia de las dos conciencias en el cerebro del doctor, después de la metempsicosis, genera un cambio en la narración. El narrador alude a la situación resultante con esta frase: «iEn su cerebro había algo de inverosímil! $\gg{ }^{53}$. El relato, que en un principio se centraba en las distintas escalas de los viajes del doctor y se constituía por los diálogos que conformaban la trama, pasa a describir la convivencia anímica. Después de esbozar una retrospectiva sobre el vínculo complementario entre el doctor y el poeta, la novela corta abandona el nivel de verosimilitud y abre paso a lo fantástico. La falta de plausibilidad científica se aprecia análogamente en la disolución del mundo diegético realista. De este modo, dicho mundo diegético se relaciona con los paradigmas médicos y lo fantástico comienza en los límites heurísticos de la ciencia positivista.

\section{DE LO FANTÁSTICO ESPIRITISTA A LA CIENCIA FICCIÓN BERGSONIANA}

Al igual que en El donador de almas, en El sexto sentido (1913) se aprecia una doble codificación del relato, una metalepsis que recuerda la estructura ficcional de algunas novelas de Théophile Gautier. En el caso de El donador de almas sobresale el aspecto paródico que pone de relieve el modelo poético de la novela espiritista por medio de las alusiones a Espirita y a Avatar. Asimismo, se manifiesta cierto pesimismo acerca de la figura del andrógino, idealizada a lo largo del siglo XIX ${ }^{54}$. No obstante, la adaptación de las estrategias de representación de Espirita desempeña un papel fundamental, pues permite una consideración sobre el vínculo entre la narrativa y otros discursos, entre ellos la ciencia. Es preciso recordar que la novela de Gautier es dictada por un espíritu. En El donador de almas esta experiencia se expresa por medio de las dos voces en la mente del protagonista. Esta conjunción deja ver una especie de doble cerebral. A finales del siglo XIX, la figura del Dop-

\footnotetext{
51 NERVO (2006), p. 253.

52 NERVO (2006), p. 256.

53 NERVO (2006), p. 261.

54 Cf. Chaves, J.R. (2005b), Andróginos: Eros y ocultismo en la literatura romántica, México, UNAM.
} 
pelgänger se vuelve un elemento explícitamente psicológico y simboliza los dos lados de la dicotomía consciente-inconsciente. Una síntesis parecida se observa en las metalepsis de la narrativa de Gautier que operan en diferentes niveles espacio-temporales, como en La mort amoureuse. A finales del siglo XIX y en la novelística de corte fantástica de Nervo, ambos niveles tienden a representarse por medio de la disyunción entre el mundo diegético codificado como real y las alucinaciones de un personaje, muchas veces construidas como universo paralelo, fantástico. Este tipo de ficcionalidad le sirve también a Freud en su análisis del deseo y su figuración en la novela Gradiva de Wilhelm Jensen en la que el psicoanalista distingue entre el nivel cotidiano, consciente - entretejido con un viaje imaginario a la Pompeya clásica-, que se desprende del deseo del protagonista por una mujer idealizada (en la narrativa de Gautier se trata de mujeres vampirescas, motivo que inicia el traslado a épocas y lugares lejanos $)^{55}$. En términos de psicoanálisis, es un paso pequeño de ese tejido ficcional a los enunciados del analizante que son interpretados por el analista en términos de lo reprimido que se desplaza de manera desfigurada en la conciencia. Ambos, el psicoanálisis temprano y la poética de la narrativa finisecular, comparten este trasfondo epistemológico. La narrativa tiende a ficcionalizar esa dualidad por medio de la desarticulación del eje espacio-temporal, de la escisión de los personajes, o de la intrusión de un elemento fantástico en un cosmos diegético configurado como realista.

En El donador de almas la búsqueda de la amada ideal es un acto de fe o una autosugestión, así lo da a entender el epígrafe que, según el autor, es una máxima de la Cábala: «Ten cuidado: jugando uno al fantasma, se vuelve fantasma» ${ }^{56}$. El alma donada aparece a partir de una carta y de la promesa de donación del poeta, es decir, la escritura se transforma en realidad. Así, existe una similitud con la teoría de la sugestión de Hippolyte Bernheim, emblema de la transición en la medicina mental hacia los modelos psíquicos: «Toute idée suggérée et acceptée tend a se faire acte» ${ }^{57}$. Al igual que en la literatura fantástica nerviana, el sentido literal se transforma en sentido figurativo. En El sexto sentido, las visiones de la amada son descritas como apariciones de

55 Un juego barroco con esta doble configuración del relato es la novela corta Mencía (Un sueño) (1907) de Nervo, que se sitúa por un lado en el Toledo del siglo XVI y por el otro, en una ciudad contemporánea a su escritura. Al igual que en el drama de Calderón, La vida es sueño, el personaje no logra distinguir entre su vida onírica y su existencia real. Cf. NeRvo (1991), vid. Mencía, Vol. 1, pp. 325-343.

56 Nervo (2006), p. 244.

57 Citado en Ellenberger, H. (2005), Die Entdeckung des Unbewußten, Zúrich, Diógenes, p. 401. 
un fantasma en la mente del personaje. Asimismo, se describe la supuesta desarticulación entre lo conciente y lo inconsciente. El sexto sentido puede considerarse una novela complementaria a El donador de almas, porque parte de la especulación científica de la anatomía cerebral y, se observa cierta revitalización del inconsciente visionario del romanticismo desde una perspectiva cientificista. Si en El donador de almas, el alma donada es la presencia inmaterial que visita al protagonista, en El sexto sentido, el protagonista acecha a su amada ideal sin que ella pueda percatarse de su presencia.

En ambas novelas cortas se combinan dos campos irreconciliables desde el punto de vista del positivismo: la ciencia empírica y la metafísica, que, no obstante, no se excluyen mutuamente desde la perspectiva de las ciencias ocultas a finales del siglo XIX ${ }^{58}$. Es significativo que a partir de esta conjunción Nervo construye la introspección en la novela corta, mofándose de las simplificaciones positivistas. El inicio de El sexto sentido tiene elementos de la ciencia ficción. Nervo esboza un paradigma racionalista a partir de la anatomía cerebral, relatando un caso de cirugía experimental en el cual se deshace la separación entre lo consciente y lo inconsciente «desplazando ligeramente un lóbulo cerebral» y «desviando un haz de nervios» ${ }^{59}$ (Nervo 1991: 361). La meta del experimento es extender la percepción temporal de modo que el paciente sea capaz de ver el futuro. Una vez derribado el «muro invisible que le esconde el futuro ${ }^{60}$ el protagonista contempla a la amada ideal, cuya futura venida espera. Esta segunda parte es de clara filiación romántica pues recuerda las visiones en Aurélie, de Gérard de Nerval. Así, el comienzo pseudo-científico es un pretexto para restaurar una visión romántica dentro de un contexto fantástico.

Respecto de la codificación psicológica, se observa el planteamiento psico-filosófico de Henri Bergson. De esta manera, el texto opera sobre una base epistemológica que supera el prejuicio positivista de la imposibilidad de la introspección y desarticula los fundamentos objetivistas del empirismo. El paciente describe su percepción modificada en términos idénticos al segundo capítulo del Essai sur les données immédiates de la conscience (1888):

Mi situación era análoga a la de un hombre que se encontrase en la cima de una montaña, y viese desde ella, de una parte el camino recorrido, de la otra el camino

58 Cf. Chaves, J.R. (2000), Teosofía y ocultismo en la España literaria de fines de siglo XIX. En Jornadas Filológicas 2000, Memoria, México, UNAM, pp. 151-157.

59 Nervo (1991), vid. El sexto sentido, Vol. 1, pp. 360-372, p. 361.

60 Nervo (1991), p. 360. 
por recorrer. Sólo que aquí, esos dos caminos estaban llenos de cosas y figuras, no en movimiento, sino inmóviles, a lo largo de los mismos. Es decir, que mi vida, ante la clara contemplación interior, se hallaba partida en dos porciones por el presente, en dos panoramas, mejor dicho, cada uno de los cuales, sin confusión, sin enredo ninguno, se desarrollaba dentro de una variedad que era unidad y una unidad que era variedad. Imposible expresar esto (y de ello me duelo y me desespero) sino con imágenes inexactas tomadas del diario vivir nuestro, y de la vieja normalidad de las cosas que nos rodean ${ }^{61}$.

Esta metáfora heurística hace referencia a un estado inefable, en el que se supera la diferencia entre la multiplicidad y la unidad; describe un concepto de tiempo, no medible, que se expresa intuitivamente por medio de imágenes y se opone categóricamente a un tiempo especializado, mesurable, construcción de la racionalidad científica. En otras palabras, procura describir su experiencia de la durée bergsoniana, aunque la idea del filósofo no incluía las visiones del futuro ${ }^{6}$.

La construcción fantástica disuelve las categorías del racionalismo como la unidad del yo, del tiempo y del lugar. La disolución del tiempo lineal como ilusión de los sentidos, tiene consecuencias en otros planteamientos relacionados con el sentido de la historia. El progreso de la humanidad, por ejemplo, se denuncia como construcción idealista. Así, el argumento de la novela corta es abiertamente irónico, ya que parte de un paradigma médico que simboliza plenamente la ideología progresista del positivismo. La cirugía cerebral hace posible una modificación neuronal que pone de relieve la relatividad de las construcciones heurísticas de la ciencia positiva en particular y la concepción teleológica del tiempo histórico en general. Esta argumentación circular se evidencia en el cuarto capítulo del texto donde el yo narrador divaga ensayísticamente sobre la imposibilidad del género humano para evolucionar. El paradigma médico inspira reflexiones sobre el progreso y el tiempo histórico en la novela corta porque, en ese momento, la medicina metal es la ciencia «moderna» por excelencia, inclusive modifica el entendimiento de la cultura.

De este modo, la última frase de la novela, enunciada por el protagonsita - que descubre la relatividad del tiempo y la imposibilidad del progreso histórico- - puede entenderse de modo irónico, no sólo en referencia a la trama novelesca (que parece ser paradójicamente inevitable), también en referencia

61 NeRVO (1991), p. 363.

62 Bergson, H. (2009), Essai sur les données immédiates de la conscience, TremBlay, J.-M. (ed). Disponible en línea en http://classiques.uqac.ca/classiques/bergson_henri/essai_ conscience_immediate/conscience_imm.html, p. 44, p. 47-52 (consultado el 11 de marzo de 2011). 
a la alusión de las construcciones temporales humanas: «Esta historia no debe tener fin, creédmelo.... ${ }^{63}$.

\section{LO PSICOPATOLÓGICO COMO JUEGO QUIJOTESCO}

La ficcionalidad en la novela corta Amnesia (1918) se presenta por medio de un narrador homodiegético cuya esposa sufre una hemorragia durante el parto y pierde la memoria y su personalidad. Esto agrada al narrador que declara padecer los caprichos de su esposa. Las construcciones ficcionales nervianas sobre la base de la psicopatología están vinculadas con el discurso de género de la época ${ }^{64}$. Así, la enfermedad en Amnesia es descrita con misoginia, pues para el narrador, la amnesia brinda la posibilidad de moldear un ser sumiso, reeducando a su mujer a partir de un estado de tabula rasa. Aquí se observa el mito de Pigmalión en un marco moderno constituido a partir de la medicina. Asimismo, la complementariedad de ambas personalidades, Luisa, una mujer fatal, y Blanca, infantil y frágil, recuerda el dualismo manifiesto en la pareja del doctor Jekyll y el señor Hyde.

La presencia de la medicina mental en este texto radica en que esta ciencia opera en diferentes niveles ficcionales. Así se evidencia la función lúdica de la literatura que se apropia de otros discursos para emplearlos de acuerdo con sus propias reglas. En el caso de Amnesia, la medicina forma parte de un juego quijotesco entre el engaño y el desengaño, es decir, el discurso científico se encuentra en el nivel metaficcional.

En la primera parte del relato, el narrador expone tres estudios de casos y teorías relacionadas con la amnesia para explicar la dolencia de su esposa. El cambio de personalidad repentino en su mujer lo explica por medio de la teoría de «la doble personalidad» ${ }^{65}$; después, trae a colación el caso de una mujer que tenía «diez personalidades distintas y enteramente independientes una de otra», lo que para el teórico apócrifo, mencionado por el narrador, equivale a «diez cerebros diferentes» ${ }^{66}$; finalmente, en el último caso citado, la personalidad del individuo se compone por diferentes «almas» y se habla de un «do-

63 Nervo (1991), p. 371.

64 Cf. Conway, C. (2008), Troubled Selves: Gender, Spiritualism and Psychopathology in the Fiction of Amado Nervo, Bulletin of Spanish Studies, 85 (4), pp. 461-476.

65 Nervo (1991), vid. Amnesia, Vol. 1, pp. 344-359, p. 346.

66 Nervo (1991), p. 347. 
minio psíquico» ${ }^{67}$. De este modo, se remite a los límites de la psicofisiología para explicar la conformación de la personalidad. Tras señalar casos de sonambulismo y fenómenos parapsicológicos que se oponen al empirismo positivista (haciendo eco de la típica conjunción de ciencia y esoterismo en la psicología inicial y en las ciencias ocultas), el narrador puntualiza:

Son estos, se dirá, hechos aún insuficientemente conocidos. Nosotros pretendemos que un hecho experimentado, observado por autoridades competentes, por inexplicado que sea, se convierte en una verdad empíricamente probada, lo que basta para que se le admita como base de deducciones futuras. El caso es inexplicable fisiológicamente: verdad útil de retener [...] Y con tales lecturas, quedé más perplejo que antes, sin rumbo en este abismo de lo fisio-psicológico inexplicable ${ }^{68}$.

La búsqueda de una explicación de la enfermedad lleva a la ruptura con el paradigma médico positivista. En la segunda parte del relato, el narrador estudia los hechos que se desprenden de la convivencia con su «nueva» esposa. Sobresalen, en oposición a los teoremas fisiológicos, nociones que comprueban una formación de la conciencia y por ende, de la personalidad a partir del lenguaje, lo que en términos ficcionales configura un juego con nociones centrales del discurso sobre el funcionamiento de la mente.

A partir del tercer capítulo, la medicina mental opera a nivel de la interacción de los personajes. Durante el segundo viaje de bodas se producen los primeros indicios de recuperación, pues la mujer comienza a reconocer algunos lugares visitados con anterioridad, esto evoca destellos de la personalidad original. Ya que teme que retorne el carácter indeseado, el narrador le explica que padece déjà vus. Esa ficcionalización es parte de un juego quijotesco en el que ya no se intercalan teorías médicas, como en la primera parte del texto, sino que la intertextualidad se establece con textos literarios que refieren temas médicos, como las obras del literato y médico Eduardo Wilde y de Charles Dickens. Las historias sobre el fenómeno del falso reconocimiento son utilizadas por el narrador para convencer a su mujer de que su reconocimiento incipiente es una ilusión:

Pero sí le referí, por curioso, lo que el mismo doctor nos recuerda de Dickens. En una de las novelas de éste, "figura un vendedor de baratijas que ejercía su comercio en la vía pública, junto a una casa grande y solemne; este hombre al ver entrar a la casa y salir de ella constantemente, ciertos individuos, dedujo que ellos la habitaban,

67 NERVO (1991), p. 348.

68 NerVo (1991), p. 349. 
y no deteniéndose en esto, les puso nombres, los acomodó en sus diversos departamentos y les atribuyó en su fecunda imaginación costumbres determinadas.

"Un día, por orden de autoridad competente, entró en la vetusta mansión la justicia, y tras de ella el público con el vendedor aludido a la cabeza, el cual hubo de desmayarse, al saber que el sujeto a quien él por tantos años había llamado mister Williams, no era tal mister Williams; que la tía Marta, era miss Peggi; que el dependiente Frank no era dependiente, sino socio y se llamaba John (no eran éstos precisamente los nombres, pero para el caso es lo mismo). En fin, que los aposentos no estaban distribuidos en la forma que él lo había adjudicado, ni respondían al plan trazado en su mente, con líneas indestructibles; en resumen, el pobre diablo experimentó una desilusión completa y dolorosa, como si la destrucción de lo que su fantasía había creado, fuera una desgracia"69.

Este juego de engaño y desengaño no sólo refleja la ilusión que el narrador procura construir para conservar el carácter sumiso de su esposa. De modo irónico, la realidad que busca construir mediante sus conocimientos médicos se evidencia como ilusoria, ya que se restituye plenamente la personalidad indeseada. Este juego metaficcional reduce la teoría médica a un «puro cuento» y muestra la inestabilidad heurística de las teorías.

Los psiquiatras y médicos William James, Pierre Janet, Henri Bergson, Jean Martin Charcot, Théodule Ribot, Eugène Azam y Santiago Ramón y Cajal, entre otros, desfilan por las novelas cortas de Amado Nervo, sobre todo en El sexto sentido y en Amnesia. La figura del médico gana presencia a lo largo de las obras de Nervo y representa un nuevo paradigma racional opuesto a la tradición. En algunos casos, se mencionan explícitamente a esas médicos para otorgarle verosimilitud a la narración. Sin embargo, los textos se trasladan al terreno de la ciencia ficción o de la literatura fantástica. Ambos géneros ponen en entredicho el materialismo limitado del paradigma científico positivista. La ficción se acerca a los presupuestos de la psicología moderna, ante todo, por medio de una combinación de ciertos elementos del legado romántico (las nociones del sueño y del inconsciente) ${ }^{70} \mathrm{y}$ de la literatura fantástica. Dichos elementos son despojados de sus connotaciones metafísicas en el marco pseudocientífico de las narraciones, que, de esta forma, se vuelven metáfora heurística.

Asimismo, con el desarrollo de la obra nerviana, las alusiones a la medicina se vuelven más explícitas y más lúdicas. Mientras que las primeras novelas

\footnotetext{
69 NerVo (1991), p. 354.

70 BÉGuin, A. (1954), El alma romántica y el sueño, México, Fondo de Cultura Econó-
} mica. 
cortas, de carácter naturalista, integran la teoría médica para estructurar la trama y esbozar los personajes, obras posteriores se emancipan de la seriedad de la racionalidad médica y juegan con las implicaciones filosóficas y psicológicas de la psiquiatría. Por medio del juego metaficcional, sus novelas cortas tardías ponen en tela de juicio la veracidad y la cientificidad de las teorías y de la institución del manicomio. Asimismo, la ficción se aleja de los fundamentos somáticos de la psiquiatría decimonónica y anticipa de manera preteórica nociones que adquieren cientificidad con la fundación de la psicología moderna. En particular, la ficción hace hincapié en el vínculo entre el deseo y su figuración, así como en la importancia de las funciones inconscientes de la mente. Estas transformaciones de la ficción deben comprenderse como reacción a la manera de concebir la cultura y la modernidad en el positivismo; a partir de la última década del siglo XIX mexicano, ambas se apreciaban en términos psicopatológicos, al igual que la construcción literaria de la sensibilidad del artista. Esta integración intensiva del discurso científico permite un primer atisbo a la formulación del autoentendimiento de las vanguardias históricas.

Recibido: 31 de octubre de 2009.

Aceptado: 23 de febrero de 2010 . 